subject are agreed, of a routine examination of the meninges in all cases in which visceral carcinoma has been complicated by the development of definite symptoms referable to the nervous system in its clinical course. It suggests, further, the danger of error which lies in the loose invoking of "toxaemia" as an explanation of disorders of nervous function for which no gross cause is readily apparent. The presence of a lymphocytic infiltration in association with the malignant one may indicate simply a meningeal reaction to the presence of foreign cells, or may in part be due to a noxious chemical activity of the latter cells.

\title{
REFERENCES
}

1. Lilienfeld und Benda. - “ Ueber einen Fall von multipler metastatischer Carcinose der Nerven und Hirnbäute." Berliner klin. Wochenschr., Vol. XXXVIII, p. 729, 1901.

2. Nonne, M. “ "Ueber diffuse Sarkomatose der Pia mater des ganzen Centralnervensystems. Deu'sch. Zeitschr. f. Nervenheilk., Vol. XXI, p. 396, 1901.

3. Oppenheim, H.- "Ueber Hirnsymptome bei Carcinomatose ohne nachweisbare Veränderungen im Gehirn." Charité Annalen, Vol. XIII, p 335, 1888.

4. Pette, H.- "Ueber diffuse Karzinose der weichen Hirn-und Rückenmarkshäute." Deutsch. Zeitschr. f. Nervenheilk., Vol. LXXIV, p. 226, 1922.

5. Saenger, A - "Ueber Hirnsymptome bei Carcinomatose." Neurol. Centralbl., No. 23, p. $1086,1901$.

6. Schwarz und Bertels.-Ueber " Meningitis " carcinomatosa. Deutsch̀. Zeitschr. $f$. Nervenheilk, Vol. XLII, p. 85, 1911. (With Bibliography.)

7. Siefert, E. - "Ueber multiple Karzinomatose des Zentralnervensystems." Münch. med. Wochenschr., Vol. XLIX, p. 826, 1902.

\section{THE IMPORTANCE OF RADIOGRAPHY IN DOUBTFUL CASES OF OPTIC ATROPHY WITH SPECIAL REFERENCE TO PITUITARY DISEASE}

BY

Major R. E. Wright, M.D.,

SUPERINTENDENT, GOVERNMENT OPHTHALMIC HOSPITAL, MADRAS

With Radiographic Prints and Notes

BY

CAPTAIN T. W. BARNARD,

RADIOLOGIST, GOVERNMENT X-RAY INSTITUTE, GENERAL HOSPITAL, MADRAS

IT is not improbable that many cases of pituitary disease, or disease in the neighbourhood of the pituitary fossa which eventually involves the hypophysis, are missed by ophthalmologists because the only obvious feature in the picture is optic atrophy. This ought not to be so, for it is to them that the majority of cases of hypophyseal involvement apply for relief. The features which tend to put the ophthalmologist off his guard are the frequency 
with which he sees optic atrophy, to which he cannot with certainty assign a cause, and the high percentage of pituitary cases which show scanty glandular symptoms. As Fisher has pointed out (Trans. of Ophthal. Soc. of the United Kingdom, Vol. XXXI, 1911), primary atrophy is the conspicuous feature of those cases which consult the ophthalmic surgeon. In order to minimize error in this connection, it is always a safe working rule to have a full $\mathrm{X}$-ray examination made of all those cases of optic atrophy in which one is unable to satisfy oneself as to the cause of the condition. Without X-ray evidence it is in certain cases impossible to arrive at a correct diagnosis. In the past two years some eight cases in which trouble in the neighbourhood of the sella was suspected have come to my notice. This is not a very high percentage as the number of patients from which these were derived was about 40,000 . Of these eight, three were not clinically sharply defined nor was the X-ray evidence positive. As the trouble in these cases could not be localized to the pituitary region they are omitted. I give below a brief clinical summary of the remaining five, together with a histopathological note on one of them and the radiographic features with prints. It will be seen that in two the clinical evidence is fairly typical, whilst in the other three, optic atrophy so overshadows all the other symptoms that without radiographs the cases might easily have remained undiagnosed.

The value of finding a high sugar tolerance in two cases is doubtful, as certain patients without pituitary trouble showed this sign equally well marked. This is interesting and may be related to the nature of the diet.

\section{CASE I}

Tumour in the pituitary region giving rise to marked neighbourhood symbtoms, and total blindness with hypopituitarism.

D. D., Eurasian female, aged 8, presented herself at the outpatient department of the Government Ophthalmic Hospital on May 2,1917. She had fallen down when in school in the previous month, and three days afterwards discovered that she could not see with the right eye. She gave a history of headache during the two previous years, When the headache was severe she had giddiness and vomiting. There had been squint during this period, but it passed off. She had also severe attacks of nose bleeding.

Condition on admission.-R.E.V. $=0$; L.E.V.=6/18. R.E. disc uniformly pale, complete atrophy, free from cupping or signs of previous inflammation. L.E. fundus. normal. Fields not taken. Nose, throat and naso-pharynx healthy. Last right upper molar decayed. Reflexes normal. Wassermann.-negative; von Pirquet.negative. Blood.-Hb. 85 per cent., polys. 65 per cent., eosinos. 
13 per cent., lymphos. 15 per cent., large monos. 7 per cent. Urine.Albumen nil, indican plus, sugar nil. No further details available.

1/9/17. - The patient took her discharge and was not seen again until her re-admission.

8/10/19.-Re-admitted. R.E.V.=O.; L.E.V.=P.L. Is very drowsy and will not take food. Pupils moderately dilated and inactive; has had headache and vomiting from time to time since she left hospital. Fundus examination :- both discs very white, vessels normal, edges sharp, primary optic atrophy.

2/5/21. - Re-admitted. I saw the case on this date for the first time. The note on the condition is as follows:- the child is underfed, thin, and undeveloped and weighs 40 pounds. The mucous membranes are pallid. There is pyorrhoea alveolaris. The skin is thin, smooth, and waxy. Secondary sexual characters are undeveloped. She has not menstruated, has no body hair, hair of the head is fine and thin. She has left torticollis. The left sternomastoid and trapezius are in spasm. There is left facial paresis. She keeps the mouth open and looks like a marked adenoid case. Speaks with a nasal intonation (on enquiry it is found that this feature was not present formerly). Adenoid growths can be seen and felt. She has tenderness over the occiput and cervical spine.

The vertebral column is straight. She is bright when spoken to, but for the most part inclined to doze. She has occasional headaches and vomiting attacks which come on suddenly and are associated with giddiness. The hands and feet are small, the fingers slender and tapering. The subcutaneous fat is scanty. Urine.-The urine is normal in reaction, but there is slight polyuria (carbohydrate tolerance not recorded). The deep reflexes are accentuated. Babinski's plantar reflex is normal on the right, abnormal on the left. The evening temperature varies irregularly. The pupils are dilated and inactive. The discs are uniformly white, laminae visible, arteries smaller than normal, edges of left disc not 'so sharp as right. Family history.-The father and mother are alive and well, also one brother and two sisters. There is no suggestion of syphilis in the family.

11/6/21. - Sent for X-ray examination. Tumour in sellar region, spinal column normal, few small opacities in lungs (See print No. 1 and note at end of article).

9/7/21. - Naso-pharynx explored. A small portion of the projecting mass of vegetations removed for examination; these were found to contain lymphoid tissue with fine calcareous particles.

14/7/21. - Died of septic meningitis.

Post-mortem.-First and second fingers introduced behind soft palate, mass of soft tissue in naso-pharynx explored. With a comparatively gentle push the fingers were made to enter the middle fossa passing through a soft gritty tissue which felt like granulation 
tissue permeated with fine calcareous particles. Portions of bone and growth hooked out; no further examination permitted.

Histopathology.-On examination of the growth, I was at first considerably puzzled as to its nature, for in parts it consisted entirely of large degenerate squamous cells, which took up the picric of the van Gieson stain. Careful study of a number of sections showed that the bulk of the tissue was composed of epithelial elements of a squamous type undergoing a hyaline degeneration. In some places there was a whorl arrangement resembling the formation of a perles in an epithelioma. A few of these squames retained their cell structure, most of them had merely an outline. In other parts there were columns of a more regular high cubical epithelium. Throughout the sections there was evidence of calcareous deposits of an amorphous nature.

The tumour apparently was one of those extra-pituitary neoplasms belonging to the group of hypophyseal growths characterised by the proliferation of epithelial elements of a squamous or pavement type, said to develop from a congenital anlage associated with the formation of the pituitary body from the anterior end of the stomatodaeum.

As far as I can find in the literature at my disposal such tumours are very uncommon. The epithelial elements tend to assume adamantine characters and undergo keratohyaline degeneration developing concentric formations. As metastases are not formed one cannot call them epitheliomata. They might perhaps be termed epithelio-blastomata, progressive but not metastatic.

The growth was probably of the variety described by Ernheim referred to by Cushing, but I am unable to obtain the original articles on the subject.

\section{CASE II}

Tumour of the pituitary region, optic atrophy the chief feature, inconspicuous glandular svmptoms suggestive of former hyperpituitarism followed by dyspituitarism.

On 7/9/21.-M., a Hindu, male, aged 21, came to the Government Ophthalmic Hospital almost blind. He noticed his sight getting dim five years ago, much worse for the past two years. Has been led by the hand for six months. Had headache and vomiting 2 years ago. A year ago had three or four fits (uncinate seizures?). At present has no headache, but gets attacks of giddiness and staggering.

Conditions. - R.E.V. $=$ H.M., L.E.V. $=$ Fingers at 9 inches. The pupils are dilated, but re-act to light and accommodation. Nothing else remarkable about eyes except the disc changes. Fundus.-No evidence of inflammatory trouble. Discs right and left show typical 
primary optic atrophy. The laminae are very distinct. Tension, normal in both eyes. The naso-pharynx is normal, also the nose; power of smell good. The cranial nerves normal. The deep reflexes are exaggerated, the plantar reflex is extensor in type. No general pressure symptoms except the giddiness and headache.

The patient looks big and massive, much more so than the average patient admitted, but it cannot be said that there is gigantism. There is no characteristic change in the skeleton. He is bull necked but the shoulders and sternoclavicular region show nothing abnormal. He has a coarse face, thick lips, a wide flat nose and a tendency to maxillary prognathism without spacing of the teeth. (It may be noted that many of the patients here show prognathism with spacing so that this feature is not of very great help, nor is the absence of crescents of the nails, since this feature is very common amongst ordinary patients.) The hands are very large and coarse, but there is no definite metacarpal thickening. The feet are small and well shaped, almost too small for the body. The hair of the head is fine, but, on the body, not excessive and normal in distribution. The skin of the body is coarse and thick; secretion about normal. Adiposity is not marked, but he is well covered and says he is getting fatter. $\mathrm{He}$ is of average intelligence, inclined to be drowsy. He does not admit sexual precocity, nor has he loss of libido now. Genitals normal. Urine.-Sp. Gr. 1016, acid, no albumen, no sugar. Total amount passed in the 24 hours less than normal, about 38 ozs. Sugar tolerance high (300 grammes glucose). Blood. - Hb. 80 per cent., polys. 60 per cent., eosinos. 18 per cent., lymphos. 20 per cent., large monos. 20 per cent., B.P. $130 \mathrm{~mm}$. Hg. Pulse.-Varies from 70 to 100 a minute. Temperature uniformly subnormal, hands always feel cold.

Syphilis.-No history, but some clinical evidence. Wassermann -negative. Tuberculosis.-No clinical evidence, von Pirquet negative. X-ray Examination.-A large growth present in the sella region (see print No. 2 and notes).

\section{CASE III}

Definite enlargement of the sella, few glandular symptoms, characteristic fields.

P., male, Hindu, aged 35, first came to the Government Ophthalmic Hospital, on May 28, 1919, complaining of defect of sight for 3 years, worse for the past 3 months. He has had headache on and off for 3 years, constant for a week, had suffered from giddiness for 3 months, no vomiting; was married twice, has three daughters by the first and one son by the second wife, the latter had one abortion. Has no nose complaint. An X-ray photograph was taken at this time which was lost. It gave no definite information. 
Vision.-R.E. $=6 / 9$; L.E. $=6 / 5$. Tension normal both eyes, right pupil sluggish, left pupil active. Eyes otherwise normal except for the appearance of the fundi. On admission there was oedema of the optic nerves and surrounding retinae with great fullness of the veins and tortuosity of the finer twigs - a mild degree of choked disc. The R. field on June 2,1919, is shown in the chart No. 1 . The nasopharynx was apparently normal; cranial nerves and deep reflexes normal. The only recorded general pressure symptoms were headache, giddiness, and choked disc as noted above. There was no

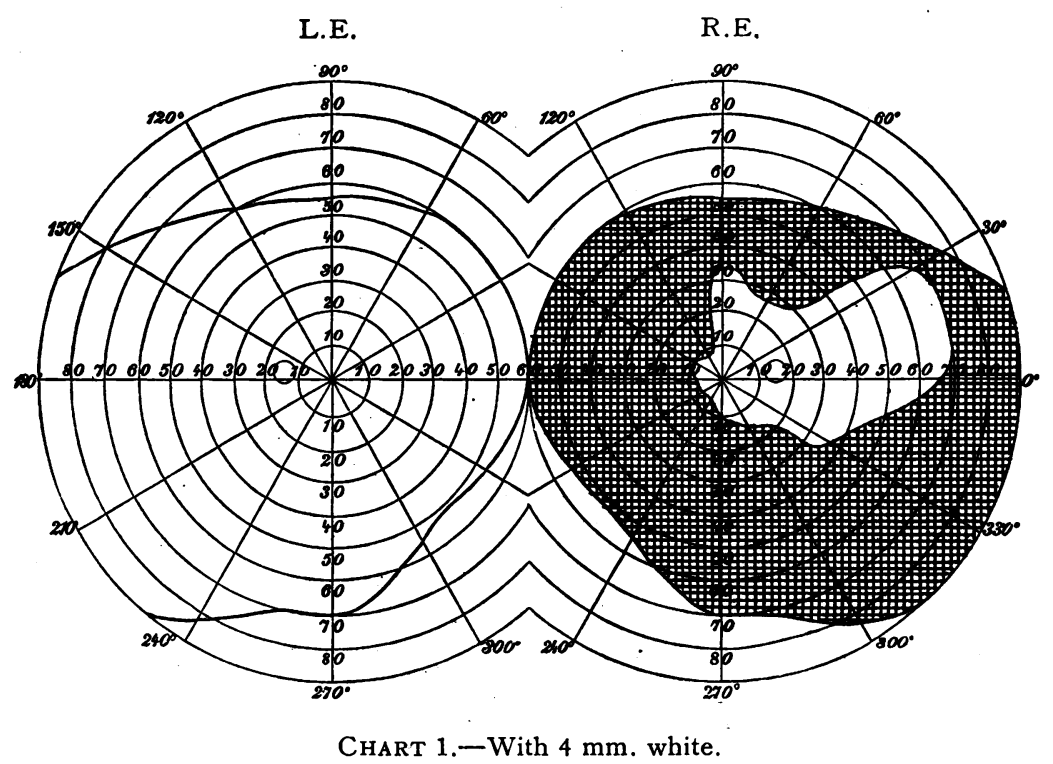

history of fits, glandular symptoms were inconspicuous, the skeleton showed nothing unusual.

The patient was a moderately tall, well-built man with healthy skin and ordinary distribution of hair, well covered, but not adipose. Distribution of fat normal. He had been very thin as a student and remained so to the age of 20 . His sexual functions were normal as also his voice and general intelligence.

Urine.-Sp. Gr. 1012, no albumin, no sugar; sugar tolerance not recorded. Normal in quantity. Blood.-Hb. 93 per cent., polys. 64 per cent., eosinos. 12 per cent., lymphos. 20 per cent., large monos. 40 per cent. The cells were normal. Blood pressure between $108-120 \mathrm{~mm}$. during the last half of 1919 . Pulse rate 80-90. Temperature remained about normal.

Syphilis. - No history or clinical evidence, Wassermann reaction negative. Tuberculosis. - No clinical evidence, von Pirquet negative. 
Progress.-There was very little change in the patient's general condition from the time he was first observed. The charts of fields from time to time are shown and the following notes give the changes in the fundus picture (see charts $2,3,4,5$ ).

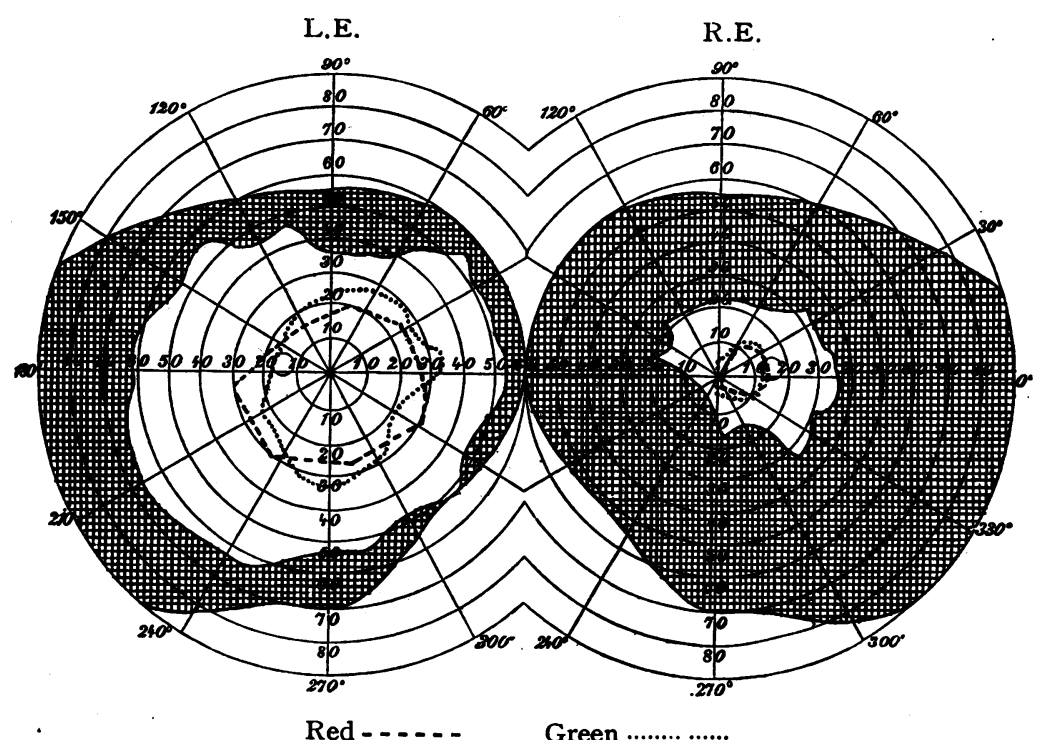

Chart 2. $-4 \mathrm{~mm}$. white and coloured objects at $33 \mathrm{~cm}$.

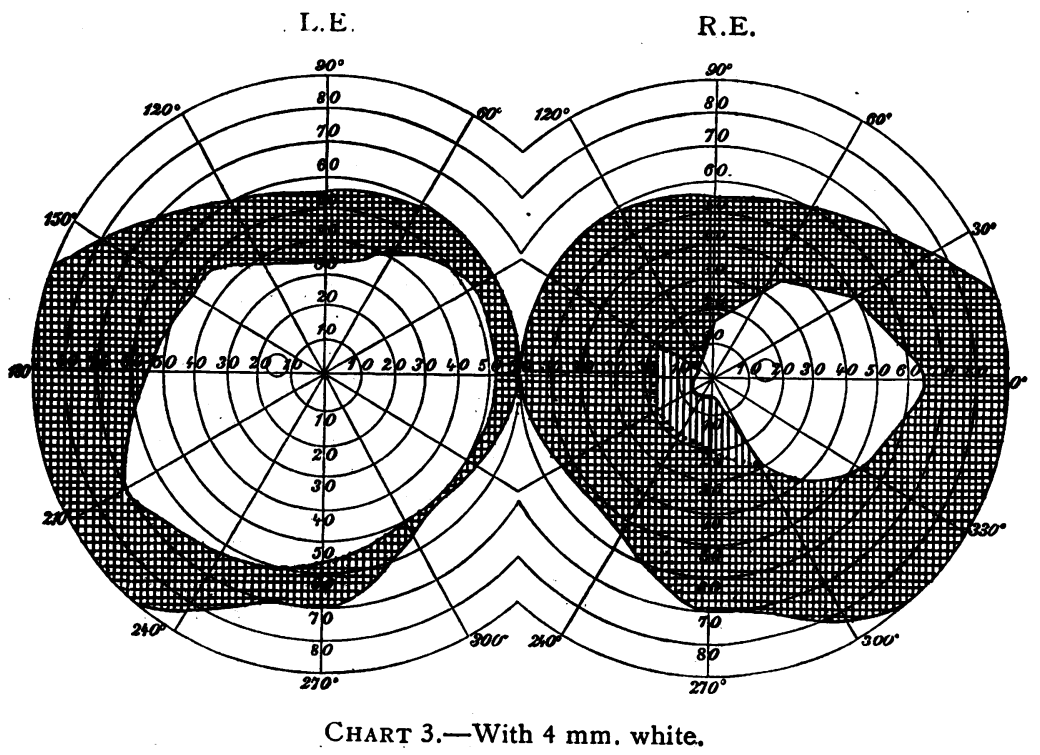


31/5/20. - The right disc is uniformly pale, its 'edges are fuzzy. There is no swelling, the veins are full. The left disc uniformly salmon pink, vessels fuller than those on the right. The superior nasal quadrant shows a considerable diminution of pigment.

L.E.

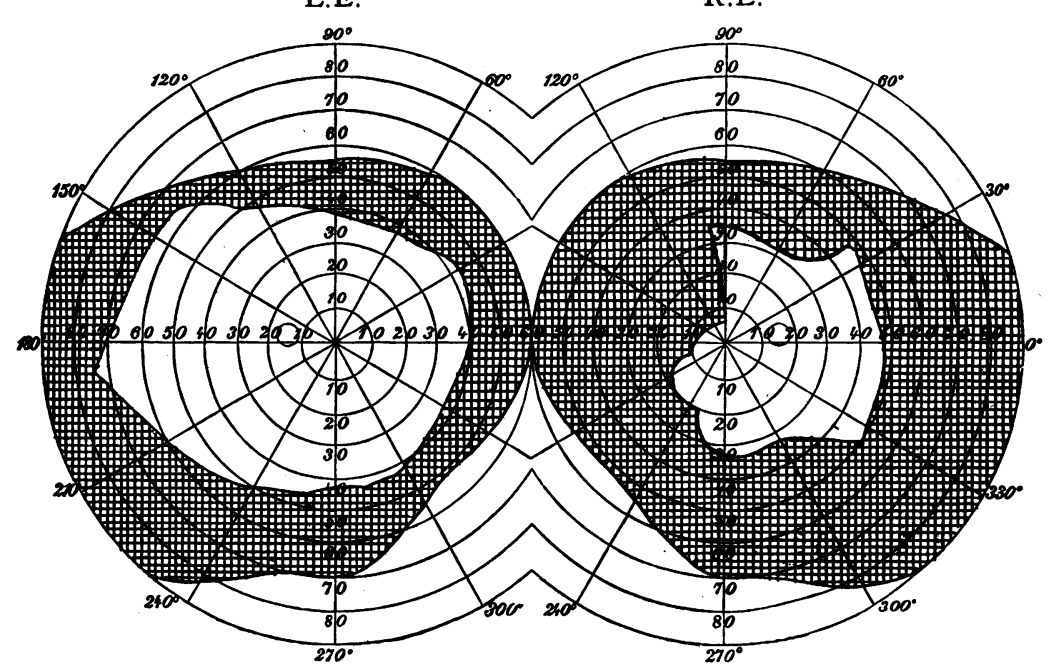

Chart 4.-Field taken with $4 \mathrm{~mm}$. white square.

L.E.

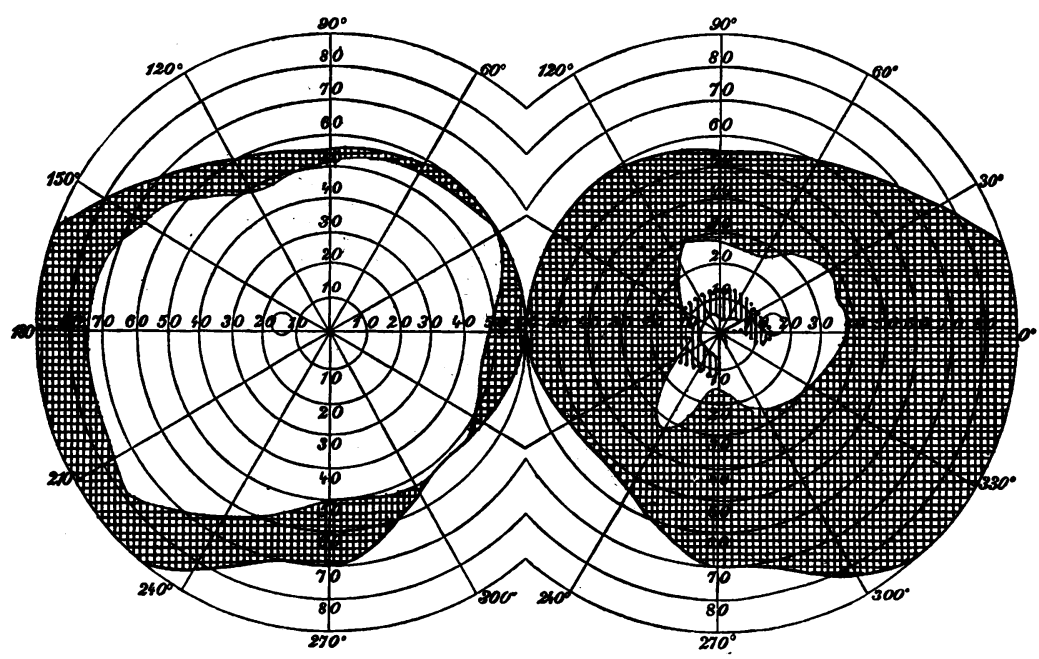

Chart 5.-With $4 \mathrm{~mm}$, white. 
2/5/21.- The right disc is now uniformly pale. It is very slightly swollen and there is a hazy edge blending with a slightly oedematous retina. The veins are engorged and the finer twigs are tortuous. The left disc is different in colour. It is pinkish and perhaps a little more swollen than the right, but the amount of swelling in either case is small. The retina is similar on both sides. Optic atrophy is commencing.

Treatment.-30/5/19. The patient was put on extract (whole gland) twice daily. This was stopped on October 6, 1919. It was recommenced in April, 1920, and continued, together with potassium iodide, till the end of 1920 . Treatment then ceased.

Further Progress. - 5/4/21. An X-ray photograph was taken by Captain Barnard who found a definite enlargement of the sella with increased markings of the vessels on the inner table. (A print of this radiograph is not shown; it is in no way different from the print which is given. See Fig. 3 at end.) Treatment was now started at the General Hospital, and the patient was put on hormotone and $\mathrm{X}$-ray exposures were given as follows :-

2/5/21. 2 sab B. through $3 \mathrm{~mm}$. aluminium R. temporal region

\begin{tabular}{|c|c|c|c|c|}
\hline $4 / 5 / 21$ & ", & ", & ", & L. \\
\hline $9 / 5 / 21$. & ", & ", & ", & $\mathrm{R}$. \\
\hline $12 / 5 / 21$. & ", & ", & $"$ & L. \\
\hline $16 / 5 / 21$. & $"$ & ", & ", & $\mathrm{R}$. \\
\hline $19 / 5 / 21$. & $"$ & " & " & L. \\
\hline $21 / 5 / 21$ & ", & , & ", & $\mathrm{R}$. \\
\hline
\end{tabular}

Patient had to leave Madras. X-ray treatment discontinued.

At this time it was noted that there was an aneurysmal dilation of the carotid in the upper part of the neck on the right side. The patient continued hormotone for some months and was then lost sight of till January 16, 1922 when the following note was made :General condition much the same, patient quite cheerful and able to carry on his business as a pleader, says he is very little fatter if at all, inclined to be lazy and to put off work, feels drowsy. Sexually there is no definite decrease in libido and power; he is not impotent. He confirms the statement above that as a student he was very thin and only started putting on flesh at the age of 20 . $\mathrm{He}$ is now 38 and is able to carry on his work quite well. A second radiograph at this time shows no change (see print No. 3 at end of article.) The patient was put on fresh sheep's gland, approximately one gland daily and allowed to go home. 


\section{CASE IV}

Enlargement of the sella with definite primary hypopituitarism and characteristic nerve involvement. Dystrophia adiposo-genitalis.

R.D., European, aged 36, consulted me on July 22, 1920. He had been quite well till 1918. Early in 1919 he began to get headaches. The sight first became affected in April, 1919. He consulted an eye specialist in the July of that year. He could at that time read and write quite well. He could still read newspapers in January, 1920, but the eyes got tired and painful after a short time. He noticed that he had become much fatter in the past two years. $\mathrm{He}$ had syphilis in 1911 and had full courses of "606" and Hg. On a second occasion (starting March, 1920) he had novarsenobillon once a week, five doses.

$27 / 7 / 20$.-R.E.V. $=6 / 60 ;$ L.E.V. $=6 / 60$. Occasional flashes of better vision. Can only read about ten minutes, then gets very tired and the sight gets blurred so that he has to discard the paper or book. Vision of the bitemporal hemianopic type. Fundus, early primary optic atrophy.

Tension normal both eyes. Pupils medium, round, symmetrical, accommodation reflex normal, light reflex present with hippus. Headache much less frequent than formerly and none at present, no giddiness. Romberg's sign negative. Has had no vomiting, nose bleeding, or fits. He feels very sluggish and has been putting on flesh very rapidly. He is a short thick-set man, well formed but for the adiposity, which is generalized. Urine.-Shows neither sugar nor albumin. Anaphrodisia marked. Fields.-Bitemporal hemianopsia very sharply marked. (See chart No. 6.)

24/7/20.-X-ray examination showed enlargement of the sella, of a shallow scooped out type. The radiographic evidence was "in favour of pituitary tumour." (The print is not available.) He was sent to England almost at once to see Col. Kirkpatrick, who has kindly furnished me with the following details :-

30/8/20.-First seen just after his arrival from Colombo. His sight had failed considerably on the voyage; his headaches had improved slightly. R.V.=Fingers near face on the nasal side; this was limited to a very small part of the nasal field.

L.V.=Fingers at 5 metres. The right field could not be taken and the left showed temporal hemianopsia. The retinal veins were full and the smaller branches were corkscrewed. The right pupil reacted very sluggishly to light. Opinion that the trouble was due to pituitary pressure was confirmed by Dr. Gordon Holmes. Cerebro-spinal fluid examined gave a negative result, this and the 
blood being reported on as normal. Symptoms increased and an operation for the relief of pressure was recommended to be performed without delay. Mr. Percy Sargent operated upon him on September 15, 1920, and reported that he found a considerable degree of general intracranial pressure, which was apparently due in part, at any rate, to the very large amount of cerebro-spinal fluid beneath the arachnoid. There was also an abnormal quantity of fluid at the base on elevating the temporal and frontal lobes; the right optic nerve and edge of the chiasma were seen, but no tumour was visible.

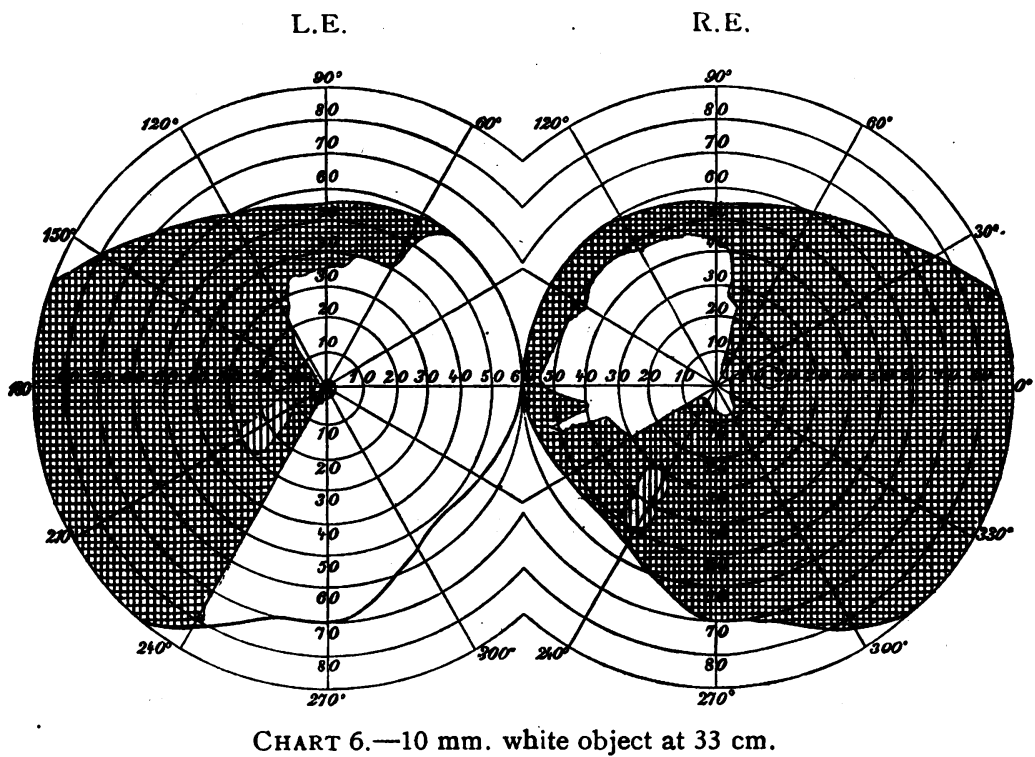

His headache disappeared and his sight improved slightly after the operation. The retinal veins lost the turgid appearance which they formerly showed. The improvement was maintained up to the end of January, 1921. He then suffered from an attack of influenza with bronchitis, gastritis, and rheumatism and the sight began to fail again. Signs of pituitary deficiency made their first appearance, the diagnosis being again confirmed by Dr. Gordon Holmes, who recommended that he should take pituitary extract and return to the East. This he did in May, 1921.

When last seen at the end of April, 1921, his left vision was $3 / 60$ in the nasal field. The nasal field was slightly contracted above and below. There was a small area in the right nasal field with a vision of $1 / 60$. 
CASE V

Optic atrophy with changes in the pituitary region revealed by radiograph, inconspicuous glandular symptoms suggestive of hyperpituitarism followed by dyspituitarism.

On the 18/2/22, T., Hindu, male, aged 30 years, was brought to the hospital blind. He states that his sight started to get dim

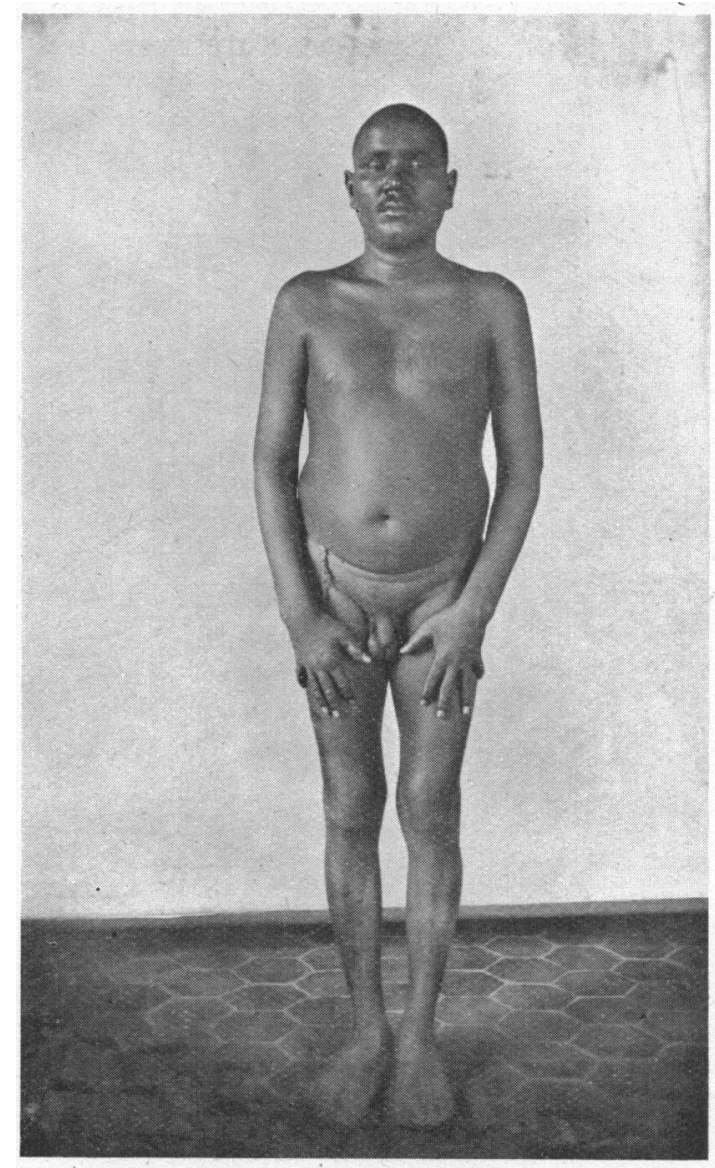

four years ago and that for the last two years he has been blind, gives a vague history of headache on and off for some time with vomiting and giddiness. He is a widower, had four children, three of whom died. At present feels quite well except for blindness.

Condition.-R.E.V. $=\mathrm{O} ;$ L.E.V. $=$ O. $、$ Pupils dilated and inactive, nothing else noted about the eyes except the disc changes.

Fundus.-Bluish disc with the laminae showing, arteries somewhat narrowed. Primary optic atrophy both eyes. Tension normal 
both eyes. Naso-pharynx normal, teeth sound, smell normal, deep reflexes normal, no symptoms of intracranial pressure. The patient looks massive and heavy with a marked stoop and head thrown forward. $\mathrm{He}$ is pot-bellied and the hands and feet are short and thick. The head is wide and massive. There are, however, no classical features of acromegaly or gigantism. Radiograph of the hands does not show the changes in the phalanges which one might expect in hyperpituitarism. There is marked adiposity of the trunk (see photograph). The testicles are small, sexual appetite was formerly normal, but has been diminished for eight years and lost altogether for two years. He has average intelligence and normal behaviour.

Urine.-Sp. Gr. 1012, acid, no albumin, no sugar. Quantity 33 to $40 \mathrm{oz}$. in 24 hours, sugar tolerance high ( 300 grammes glucose).

$\mathrm{X}$-Ray Examination.-Sella Turcica is elongated extending under the anterior clinoid processes. Posterior clinoid processes absent. There is poor definition in the pituitary region and the fossa seems to be enlarged downwards and forwards (see print No. 4). The patient was kept under observation for four months and during this time was treated with mercury and potassium iodide. There was no change in condition at the end of this time nor was anything observed of importance. He never complained or showed that he suffered any discomfort.

Blood.-Polys. 70 per cent., eosinos. 10 per cent., lymphos. 16 per cent., monos. 4 per cent. Blood pressure $130 \mathrm{~mm}$. Hg. Syphilis.No clinical evidence. Wassermann-negative. Tuberculosis.No evidence.

\section{Radiographic Notes}

\section{No. I}

The whole outline of the sella Turcica is obliterated. There is total destruction of the posterior clinoids. The anterior clinoids are partially destroyed and the sphenoidal sinus shows evidence of invasion.

The vertebral column appears normal and the lungs are fairly clear. Tumour of the pituitary region. (See print 1 ).

\section{No. II}

An apparently enlarged sella Turcica. There is partial destruction of the clinoids and invasion of the sphenoidal sinus. The whole vault shows evidence of pressure. A faint outline of the pituitary fossa is seen which rather suggests only partial destruction. Nothing definitely absormal in the metacarpal bones.

Growth probably external to sella. (See print 2). 


\section{No. III}

A large, deep, sella Turcica. The clinoids are present but the posterior processes appear "thin." The vessel grooves are abnormally marked.

Pituitary enlargement, with expansion of sella. (See print 3).

\section{No. IV}

The sella Turcica is elongated, extending well under the anterior clinoids. The posterior clinoid processes are destroyed. There is some extension downwards, probably involving the sphenoidal sinus.

Extra-pituitary growth.

Thickening of the metacarpals is doubtful. (See print 4).

\section{PRINT 5}

Dry normal skull.

No. 1.-D.D. 


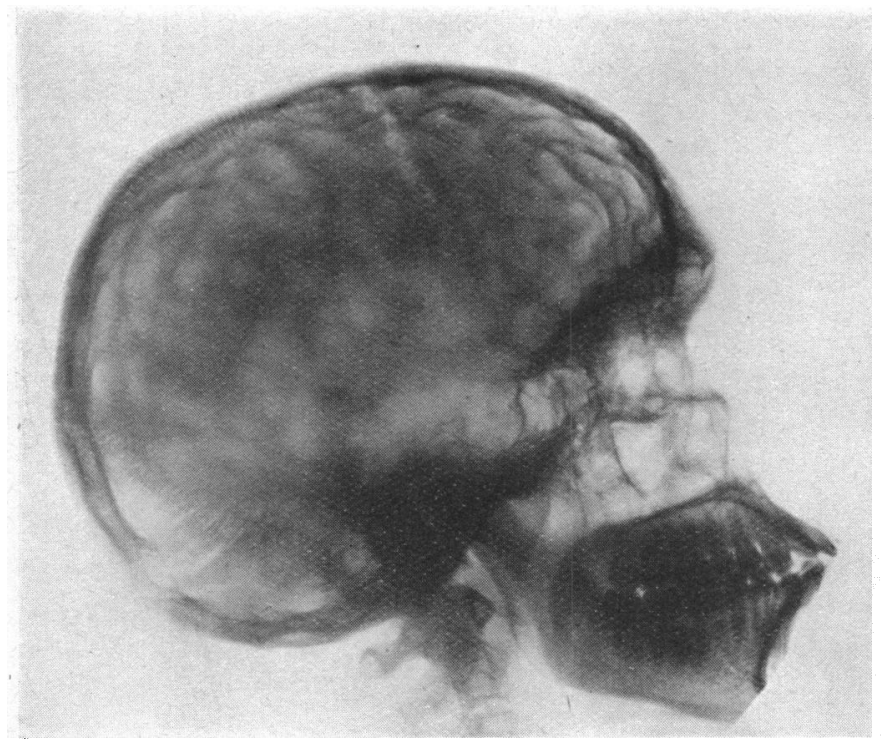

No. 2.-M.

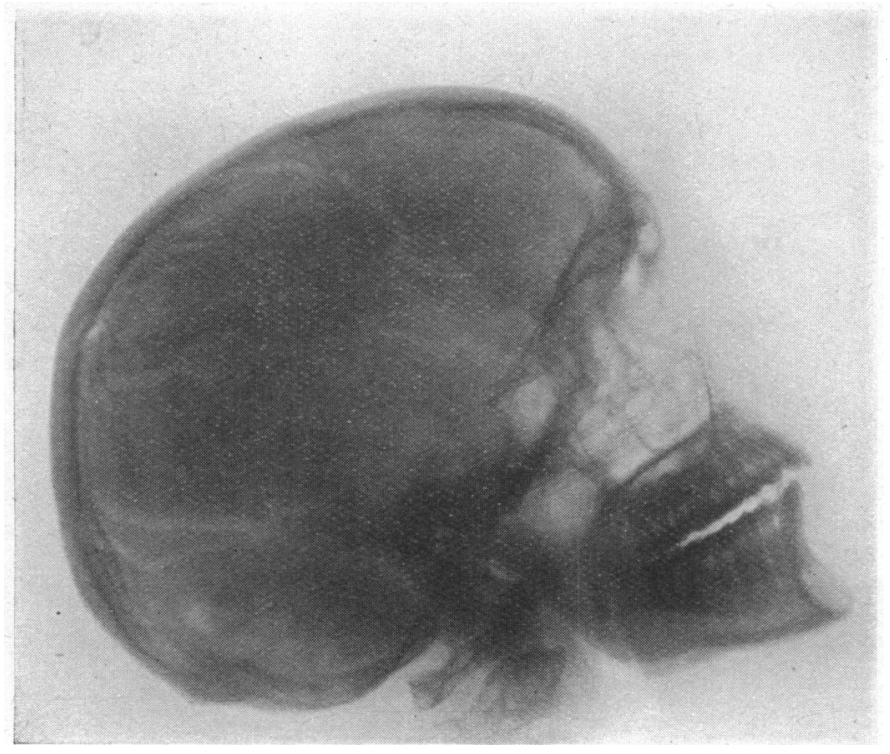

No. 3.-P. 


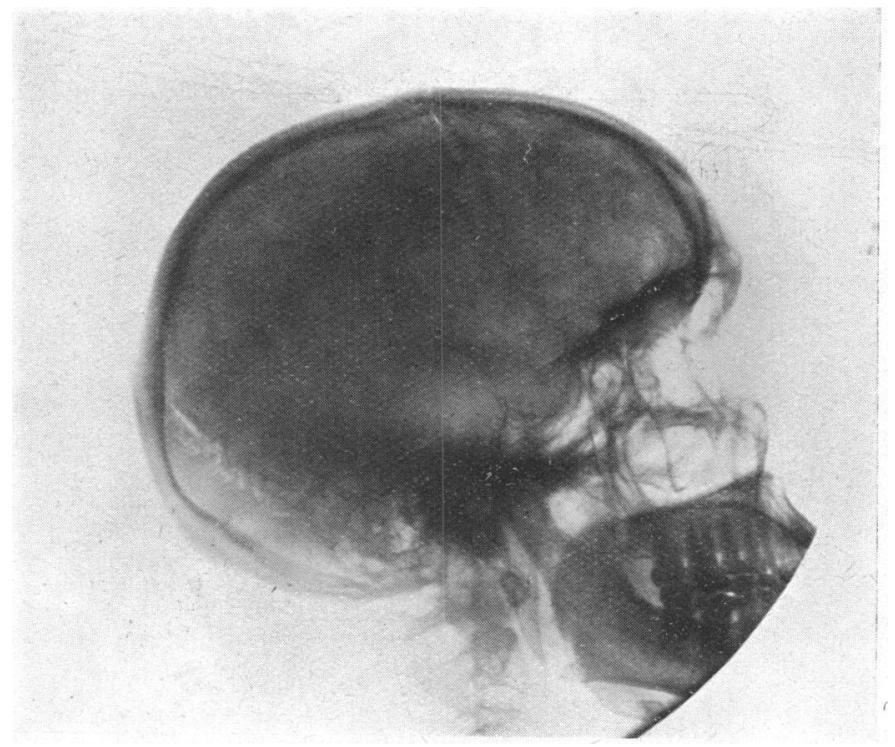

No. 4. $-\mathrm{T}$.

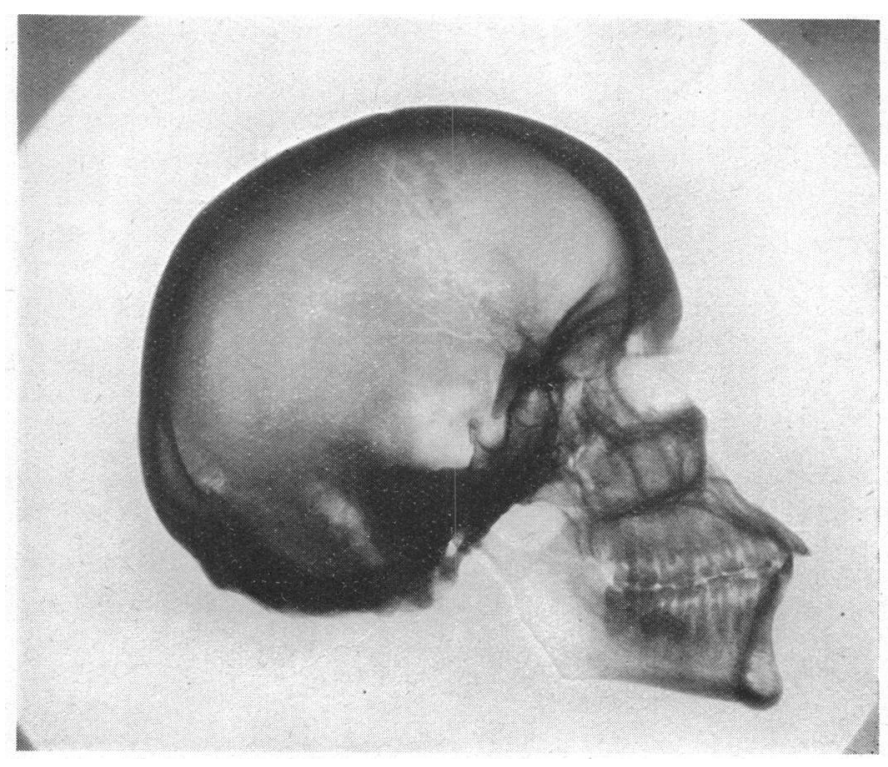

PRINT 5.-Dry skull for comparison-normal. 